\title{
Clinical phenotypes and heath-related quality of life of COPD patients in a rural setting in Malaysia - a cross-sectional study
}

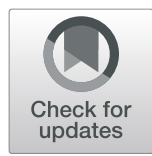

Chee-Shee Chai ${ }^{1 *}$ (D), Sumastika Bt Mos ${ }^{2}$, Diana-Leh-Ching Ng${ }^{1}$, Greta-Miranda-Kim-Choo Goh², Anselm-Ting Su', Muhammad Amin B. Ibrahim ${ }^{4}$, Aisya Natasya Bt Musa ${ }^{4}$, Seng-Beng Tan ${ }^{5}$, Yong-Kek Pang ${ }^{5}$ and Chong-Kin Liam ${ }^{5}$

\begin{abstract}
Background: The Spanish chronic obstructive pulmonary disease (COPD) guideline phenotypes patients according to the exacerbation frequency and COPD subtypes. In this study, we compared the patients' health-related quality of life (HRQoL) according to their COPD phenotypes.

Methods: This was a cross-sectional study of COPD patients who attended the outpatient clinic of the Serian Divisional Hospital and Bau District Hospital from 23th January 2018 to 22th January 2019. The HRQoL was assessed using modified Medical Research Council (mMRC), COPD Assessment Test (CAT), and St George's Respiratory Questionnaire for COPD (SGRQ-c).

Results: Of 185 patients, 108 (58.4\%) were non-exacerbators (NON-AE), 51 (27.6\%) were frequent exacerbators (AE), and the remaining 26 (14.1\%) had asthma-COPD overlap (ACO). Of AE patients, 42 (82.4\%) had chronic bronchitis and only 9 (17.6\%) had emphysema. Of the 185 COPD patients, 65.9\% had exposure to biomass fuel and $69.1 \%$ were ex- or current smokers. The scores of mMRC, CAT, and SGRQ-c were significantly different between COPD phenotypes $(p<0.001)$. There were significantly more patients with mMRC $2-4$ among AE (68.6\%) $(p<0.001)$, compared to those with ACO (38.5\%) and NON-AE (16.7\%). AE patients had significantly higher total CAT $(p=0.003 ; p<0.001)$ and SGRQ-c (both $p<0.001$ ) scores than those with ACO and NON-AE. Patients with ACO had significantly higher total CAT and SGRQ-c (both $p<0.001$ ) scores than those with NON-AE.

AE patients had significantly higher score in each item of CAT and component of SGRQ-c compared to those with NON-AE (all $p<0.001)$, and ACO [ $(p=0.003-0.016 ; p=<0.001-0.005)$ except CAT 1, 2 and 7. ACO patients had significantly higher score in each item of CAT and component of SGRQ-c ( $p=<0.001-0.040 ; p<0.001)$ except CAT 2 and activity components of SGRQ-c.

Conclusions: The HRQOL of COPD patients was significantly different across different COPD phenotypes. HRQoL was worst in AE, followed by ACO and NON-AE. This study supports phenotyping COPD patients based on their exacerbation frequency and COPD subtypes. The treatment of COPD should be personalised according to these two factors.
\end{abstract}

Keywords: Chronic obstructive pulmonary disease, Clinical phenotypes, Health-related quality of life, Exacerbators, Asthma overlap

\footnotetext{
* Correspondence: cschai@unimas.my

${ }^{1}$ Department of Medicine, Faculty of Medicine and Health Science, University

Malaysia Sarawak, Kota Samarahan, Sarawak, Malaysia

Full list of author information is available at the end of the article
}

\section{$\triangle B M C$}

(c) The Author(s). 2020 Open Access This article is licensed under a Creative Commons Attribution 4.0 International License, which permits use, sharing, adaptation, distribution and reproduction in any medium or format, as long as you give appropriate credit to the original author(s) and the source, provide a link to the Creative Commons licence, and indicate if changes were made. The images or other third party material in this article are included in the article's Creative Commons licence, unless indicated otherwise in a credit line to the material. If material is not included in the article's Creative Commons licence and your intended use is not permitted by statutory regulation or exceeds the permitted use, you will need to obtain permission directly from the copyright holder. To view a copy of this licence, visit http://creativecommons.org/licenses/by/4.0/ The Creative Commons Public Domain Dedication waiver (http://creativecommons.org/publicdomain/zero/1.0/) applies to the data made available in this article, unless otherwise stated in a credit line to the data. 


\section{Background}

Chronic obstructive pulmonary disease (COPD) is a common, preventable, and treatable airway disease characterized by persistent respiratory symptoms and airflow limitation, due to inflammatory response of the airway and lung tissue to noxious particles or gases [1]. Worldwide, COPD is currently the fourth leading cause of death and is expected to rank number three by 2030 [2]. It also ranks second in the disease burden measured by the disability-adjusted life-years, [3] causing substantial socioeconomic burden in many countries [1].

COPD phenotype is defined as a single or combination of disease attributes that describe the differences between individuals with COPD according to their clinically meaningful outcomes, such as exacerbation, symptoms, rate of disease progression, response to therapy, and mortality risk [4]. The idea of conceptualizing different COPD phenotypes came from Snider in 1989, when "chronic bronchitis", "emphysema" and "asthmatic" were presented in three overlapping circles in a non-proportional Venn diagram [5]. In 2012, the Spanish Society of Pulmonology and Thoracic Surgery proposed to phenotype COPD based on the exacerbation frequency and existing COPD subtypes [6].

Health-related quality of life (HRQoL) is defined as an individual's happiness or satisfaction with an aspect of his/her life which is affected by physical, mental, emotional and social health [7]. Impaired HRQoL is common in COPD patients due to the troublesome respiratory symptoms, limited physical activity, psychological distress, sleep disturbance and concomitant comorbidities [8]. While there have been many studies to determine the impact of COPD on the patients' HRQoL, studies that specifically compare HRQoL across different COPD phenotypes are limited, particularly in Asian countries and in the rural setting.

In this study, we aimed to compare the HRQoL of patients with COPD attending the hospitals in rural area of Malaysia based on their clinical phenotype. We hypothesize that COPD patients with frequent exacerbation and chronic bronchitis have the worst HRQoL.

\section{Methods}

\section{Study design and patients}

We conducted a cross-sectional study on patients with COPD attending the outpatient clinics of the Serian Divisional Hospital and Bau District Hospital from 23th January 2018 to 22th January 2019. Both hospitals are primary care centres that serve the rural population of southern Sarawak, a state in Malaysia located in northern Borneo Island. All patients were aged 35 years and above, with the ratio of post-bronchodilator forced expiratory volume in one second $\left(\mathrm{PB}-\mathrm{FEV}_{1}\right)$ to postbronchodilator forced vital capacity in six seconds (PB-
$\left.\mathrm{FVC}_{6}\right)<0.7$. Patients with clinical or radiological diagnosis of other chronic lung diseases (such as bronchiectasis and interstitial lung disease), active tuberculosis and lung tumours were excluded. The estimated minimum sample size for the study was 140 based on the prevalence of $10.1 \%$ in previous study at $5 \%$ of Type- 1 error and $5 \%$ of precision $[9,10]$. The primary objective of this study was to compare the modified Medical Research Council (mMRC) score, total COPD Assessment Tool (CAT) score and total St George's Respiratory Questionnaire COPD (SGRQ-c) score of patients with different COPD phenotypes. The score of each item of CAT and each component of SGRQ-c of different COPD phenotypes were compared as a secondary objective. Written informed consent was obtained from every patient. Ethics approval was obtained from the Medical Research and Ethics Committee of the National Medical Research Registry of Malaysia (NMRR-17-2549$38,621)$ and the respective hospitals. The study was conducted in accordance to the Declaration of Helsinki.

\section{Procedure}

We consecutively identified eligible patients from the outpatient clinics of both hospitals. Patient demographic and clinical data were acquired from face-to-face interview and the case notes.

Never-smokers were individuals who had smoked < 100 cigarettes in their lifetime [11]. Ex-smokers and current-smokers were defined as those who smoked $\geq 100$ cigarettes in their lifetime, the former having quitted smoking for at least a year at the time of interview [11]. Biomass exposure was defined as exposure to biomass smoke from the burning of wood or charcoal for $\geq 100 \mathrm{~h}$ per year [12]. PB-FEV 1 was expressed in percent of predicted value based on the patients' age, gender, height, and ethnicity (PB- $\mathrm{FEV}_{1} \%$ predicted) [13]. A severe exacerbation was defined as an exacerbation that required hospital admission, while a moderate exacerbation was defined as an exacerbation that required outpatient treatment with corticosteroids and/or antibiotic [14]. The total number of exacerbations in this study only included severe and moderate exacerbations because these types of exacerbations and not mild ones are associated with an increased risk of future exacerbations [1]. The phenotypes of COPD were defined according to the Spanish COPD guideline (GesPOC) 2017 [15]. A non-exacerbator phenotype (NON-AE) was defined as having no severe exacerbation and $\leq$ one episode of moderate exacerbation in the past 1 year. Exacerbator phenotype (AE) was defined as having any severe exacerbation or $\geq$ two episodes of moderate exacerbations in the past 1 year. AE was further divided into chronic bronchitis (AE-CB) and emphysema (AE NON-CB). The former was defined by the presence of cough and 
sputum for $\geq 3$ months in a year for two consecutive years [16]; while the latter was defined by the presence of air-trapping on examination or investigations [17]. Asthma-COPD overlap phenotype (ACO) included patients who had previously been diagnosed as bronchial asthma (BA); or had PB-FEV $1 \geq 15 \%$ and $\geq 400 \mathrm{ml}$ improvement over pre-bronchodilator $\mathrm{FEV}_{1}$; or blood eosinophil $\geq 300$ cells/mm $[3,18]$.

The patients' HRQoL was assessed using mMRC, CAT and SGRQ-c questionnaires. Patients answered these questionnaires independently in original English version, or validated Malay/Chinese version. They could obtain explanation from the investigators if there was any problem with understanding the questionnaires. mMRC only measured the severity of dyspnea: no dyspnea except on strenuous activity - 0 ; dyspnea when walking uphill -1 ; walked slower than people of the same age because of dyspnea - 2; dyspnea after walking $100 \mathrm{~m}$ on level ground and needed to stop for breath -3 ; and dyspnea when dressing or too dyspnoeic to leave home - 4 [19]. mMRC $0-1$ was defined as low symptom, while 2-4 was defined as high symptom [1]. Eight items, each with score ranging $0-5$ are measured in the CAT questionnaire. These included cough - CAT 1; sputum - CAT 2; chest tightness - CAT 3; dyspnea - CAT 4; activity limitation - CAT 5; confidence to leave home - CAT 6; sleep - CAT 7; and energy - CAT 8 [20]. The total CAT score in normal individuals is $\leq 6$ [21]. The SGRQ-c questionnaire consists of three components. The symptoms component consists of questions 1-7; activity component consists of questions 9 and 12; and impact component consists of questions 8, 10, 11, 13 and 14 [22]. The total score of SGRQ-c, as well as the score of each component range $0-100 \%$. The SGRQ-c score for normal individuals is $\leq 6 \%$; symptoms component $\leq 12 \%$; activity component $\leq 9 \%$; and impact components $\leq 2 \%$ [23]. For all questionnaires, higher scores denote poorer HRQoL.

\section{Statistical analysis}

Categorical variables are presented as percentages. The difference between clinical phenotypes was compared using the chi-squared test, with post-hoc analysis taking adjusted standardized residual of $>2$ as significant. Continuous variables are presented as the mean \pm standard deviation (SD), or median with interquantile range. Differences between clinical phenotypes were compared using one-way ANOVA test or Kruskall-Wallis $\mathrm{H}$ test. The post-hoc analysis was performed using Tukey test or Dunn's procedure with a Bonferroni adjustment, respectively. The significant $p$-value in this study was $<0.05$. Statistical analyses were performed using the software package, Statistical
Package for the Social Sciences (SPSS for Windows version 23.0, SPSS Inc., Chicago, IL, USA).

\section{Results \\ Demographic and clinical characteristics}

We included 185 patients in this study (Fig. 1). Their demographic and clinical characteristics are described in Table 1. Patients were mostly males, natives of the state of Sarawak, current or ex-smokers and had biomass fuel exposure.

One hundred and eight (58.4\%) patients belonged to the NON-AE phenotype, $51(27.6 \%)$ patients were $\mathrm{AE}$ phenotype, and the remaining $26(14.1 \%)$ patients had ACO. Of AE patients, $42(82.4 \%)$ had chronic bronchitis and only 9 (17.6\%) had lung emphysema. AE patients were significantly older than those with ACO (67.9 \pm 10.0 versus $60.5 \pm 14.0$ years, $p=0.024)$ or $\mathrm{NON}-\mathrm{AE}$ $(67.9 \pm 10.0$ versus $60.5 \pm 11.6$ years, $p=0.001)$. The smoking intensity in terms of pack-years of AE patients was significantly higher than that of NON-AE patients $(22.5 \pm 19.5$ versus $14.3 \pm 14.2$ pack years, $p=0.012)$, but not significantly different from that of ACO patients. There were significantly more female patients with $\mathrm{ACO}$ (42.3\%) compared to AE (13.7\%) or NON-AE (23.1\%) $(p=0.019)$. The total exacerbation episodes of ACO patients were significantly lower than that of $\mathrm{AE}$ patients $(0.2 \pm 0.4$ versus $4.7 \pm 3.4, p<0.001)$. Otherwise, there was no significant difference in ethnicity, smoking status, biomass exposure, and $\mathrm{PB}-\mathrm{FEV}_{1}$ between the COPD phenotypes.

The mean scores of mMRC, CAT, and SGRQ-c were significantly different across different COPD phenotypes (all $p<0.001$ ) (Table 2). A significantly higher percentage of $\mathrm{AE}$ patients had mMRC 2-4 (68.6\%), compared to ACO patients (38.5\%) and NON-AE patients (16.7\%). Patients with AE had significantly higher total CAT and SGRQ-c scores than those with ACO $(17.3 \pm 9.5$ versus $11.7 \pm 8.6, p=0.003 ; 53.5 \pm 22.7 \%$ versus $34.4 \pm 19.5 \%$, $p<0.001)$ and NON-AE $(17.3 \pm 9.5$ versus $5.5 \pm 4.7$, $p<0.001 ; 53.5 \pm 22.7 \%$ versus $16.4 \pm 14.8 \%, p<0.001$ ) Patients with ACO also had significantly higher total CAT and SGRQ-c scores than those with NON-AE $(11.7 \pm 8.6$ versus $5.5 \pm 4.7, p<0.001 ; 34.4 \pm 19.5 \%$ versus $16.4 \pm 14.8 \%, p<0.001)$.

Patients with AE had significantly higher score in each item of CAT and each component of SGRQ-c compared to those with NON-AE (all $p<0.001$ ) (Fig. 2 and Fig. 3). Patients with $\mathrm{AE}$ also had significantly higher score in CAT $3(p=0.004)$, CAT $4(p=0.008)$, CAT $5(p=0.013)$, CAT $6(p=0.003)$ and CAT $8(p=0.016)$; as well as symptoms $(p<0.001)$, activities $(p<0.001)$, and impacts $(p=0.005)$ components of SGRQ-c, when compared to ACO patients. Compared to NON-AE patients, ACO patients had significantly higher score in each item of 
236 COPD patients attended outpatient clinic of the Serian Divisional Hospital and Bau District Hospital from $23^{\text {th }}$ January 2018 to $22^{\text {th }}$ January 2019

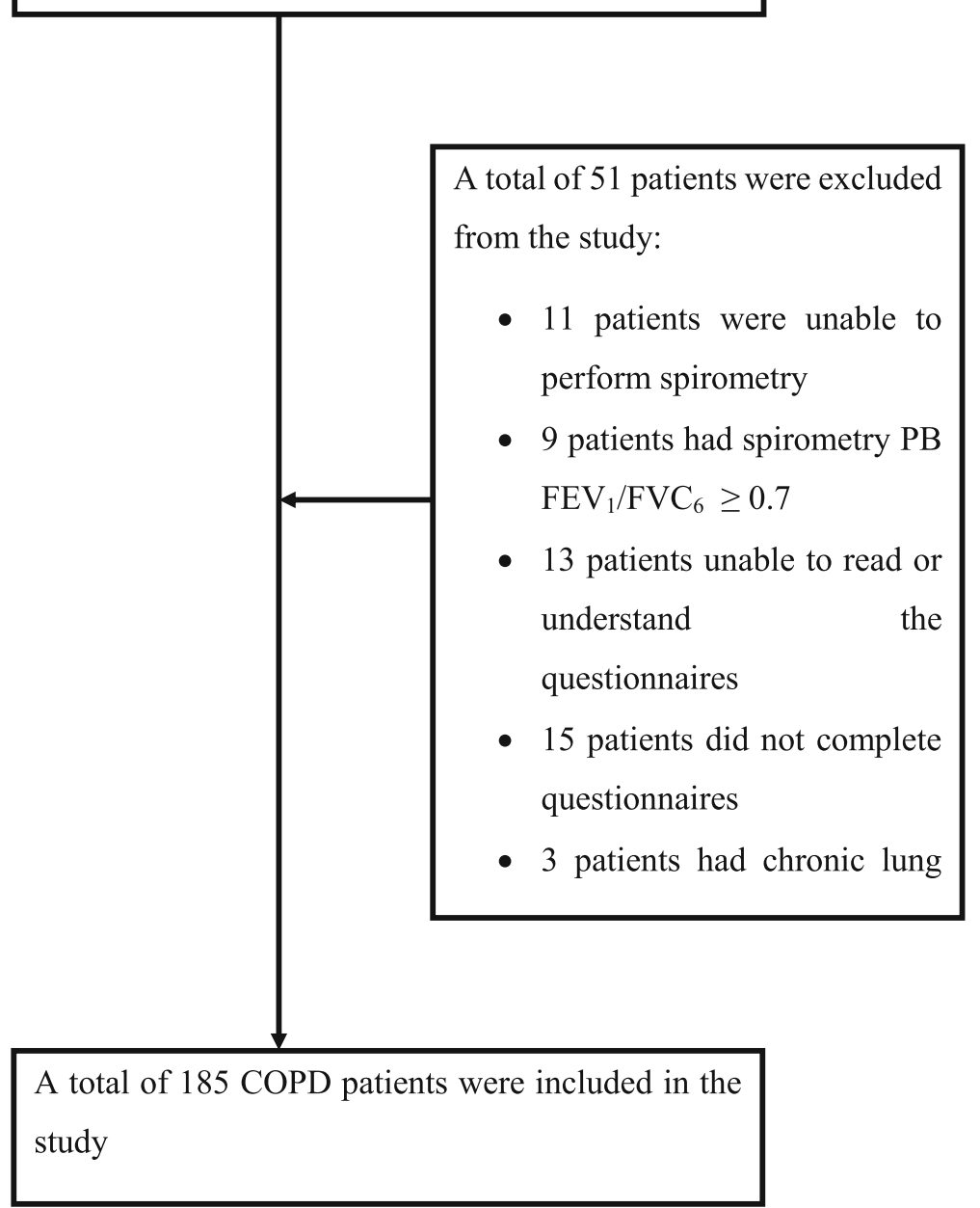

Fig. 1 Algorithm of patients' recruitment in the study

CAT ( $p=<0.001-0.040)$ except CAT 2; as well as symptoms and impact components of SGRQ-c $(p<0.001)$.

The total CAT and SGRQ-c scores of the only nine AE NON-CB patients were significantly higher than that of NON-AE patients $(12.6 \pm 9.1$ versus $5.5 \pm 4.7, p=$ $0.018 ; 47.6 \pm 18.5 \%$ versus $16.4 \pm 14.8<0.001$ ), but were not significantly different compared to those of $\mathrm{AE}-\mathrm{CB}$ or ACO patients, respectively.

\section{Discussion}

The most frequent COPD phenotype in this unselected population in the rural setting of Malaysia was NON$\mathrm{AE}$, followed by the AE-CB, ACO and AE NON-CB. Patients with $\mathrm{AE}$ were significantly older and smoked more cigarettes, while patients with ACO were predominantly female. Regardless of the COPD phenotypes, biomass fuel exposure was a common risk factor of COPD among them. Close to two-thirds of the patients were exposed to biomass fuel, mainly due to the seasonal open burning in agriculture activities.

The HRQoL of patients with AE and ACO was markedly impaired compared to normal individuals. Meanwhile, the HRQoL of patients with NON-AE was reduced when measured by SGRQ-c but not by CAT. The worst HRQoL was reported in patients with $\mathrm{AE}$ followed by those with ACO. The HRQoL of patients with $\mathrm{AE}$ was significantly worse than that of ACO and NON-AE while the HRQoL of ACO patients was significantly worse than the HRQoL of NON-AE patients. A similar pattern was also observed in each item of CAT and each component of SGRQ-c, except that the differences were not significant in cough, sputum, and sleep 
Table 1 Demographic and clinical characteristics of 185 patients according to COPD phenotypes

\begin{tabular}{|c|c|c|c|c|c|}
\hline \multirow[t]{2}{*}{ Characteristic } & \multirow{2}{*}{$\begin{array}{l}\text { No. of } \\
\text { patients, } \\
n \\
185\end{array}$} & \multicolumn{4}{|c|}{ COPD phenotype, n (\%) } \\
\hline & & $\begin{array}{l}\text { NON-AE } \\
108(58.4)\end{array}$ & $\begin{array}{l}\text { ACO } \\
26(14.1)\end{array}$ & $\begin{array}{l}\mathrm{AE} \\
51(27.6)\end{array}$ & $p$-value \\
\hline \multirow[t]{2}{*}{ Age, years (mean $\pm S D, 95 \% \mathrm{Cl}$ ) } & $62.5 \pm 11.9$ & $60.5 \pm 11.6$ & $60.5 \pm 14.0$ & $67.9 \pm 10.0$ & 0.001 \\
\hline & $60.8-64.3$ & $58.3-62.7$ & $54.9-66.2$ & $65.1-70.7$ & \\
\hline \multicolumn{6}{|l|}{ Gender, n (\%) } \\
\hline Male & $142(76.8)$ & $83(76.9)$ & $15(57.7)$ & $44(86.3)$ & 0.019 \\
\hline Female & $43(23.2)$ & $25(23.1)$ & $11(42.3)$ & $7(13.7)$ & \\
\hline \multicolumn{6}{|l|}{ Ethnicity, n (\%) } \\
\hline Malay & $31(16.8)$ & $12(11.1)$ & $6(23.1)$ & $13(25.5)$ & 0.161 \\
\hline Chinese & $20(10.8)$ & $14(13.0)$ & $2(7.7)$ & $4(7.8)$ & \\
\hline Native of the state of Sarawak & $134(72.4)$ & $82(75.9)$ & $18(69.2)$ & $34(66.7)$ & \\
\hline \multicolumn{6}{|l|}{ Smoking status, n (\%) } \\
\hline Never smoker & $57(30.9)$ & $35(32.4)$ & $11(42.3)$ & $11(21.6)$ & 0.151 \\
\hline Ex- or current smoker & $128(69.1)$ & $73(67.6)$ & $15(57.7)$ & $40(78.4)$ & \\
\hline Biomass fuel exposure, $n(\%)$ & & & & & 0.249 \\
\hline No & $63(34.1)$ & $34(31.5)$ & $7(26.9)$ & $22(43.1)$ & \\
\hline Yes & $122(65.9)$ & $74(68.5)$ & $19(73.1)$ & $29(56.9)$ & \\
\hline Risk for COPD, n (\%) & & & & & 0.430 \\
\hline Cigarette smoking & $63(34.1)$ & $34(31.5)$ & $7(26.9)$ & $22(43.1)$ & \\
\hline Biomass fuel exposure & $49(26.5)$ & $31(28.7)$ & $10(38.5)$ & $8(15.7)$ & \\
\hline Both & $73(39.4)$ & $43(39.8)$ & $9(34.6)$ & $21(41.2)$ & \\
\hline \multirow[t]{2}{*}{ Smoking intensity, pack-years (mean $\pm \mathrm{SD}, 95 \% \mathrm{Cl}$ ) } & $17.1 \pm 16.9$ & $14.3 \pm 14.2$ & $18.1 \pm 19.6$ & $22.5 \pm 19.5$ & 0.016 \\
\hline & $14.7-19.6$ & $11.6-17.0$ & $10.2-26.0$ & $17.0-28.0$ & \\
\hline \multirow[t]{2}{*}{$\mathrm{PB}-\mathrm{FEV}_{1}, \%($ mean $\pm \mathrm{SD}, 95 \% \mathrm{Cl})$} & $42.8 \pm 19.5$ & $43.6 \pm 20.1$ & $44.4 \pm 17.9$ & $40.4 \pm 19.3$ & 0.566 \\
\hline & $40.0-45.7$ & $39.8-47.4$ & $37.2-51.7$ & $34.9-45.8$ & \\
\hline \multicolumn{6}{|l|}{ Exacerbations, episode (mean $\pm \mathrm{SD}, 95 \% \mathrm{Cl}$ ) } \\
\hline \multirow[t]{2}{*}{ Total } & $1.4 \pm 2.7$ & $0.2 \pm 0.4$ & $0.2 \pm 0.4$ & $4.7 \pm 3.4$ & $<0.001$ \\
\hline & $1.0-1.8$ & $0.1-0.3$ & $0.1-0.4$ & $3.8-5.7$ & \\
\hline \multirow[t]{2}{*}{ Moderate } & $1.1 \pm 2.2$ & $0.2 \pm 0.4$ & $0.2 \pm 0.4$ & $3.6 \pm 2.9$ & $<0.001$ \\
\hline & $0.8-1.4$ & $0.1-0.3$ & $0.1-0.4$ & $2.8-4.4$ & \\
\hline \multirow[t]{2}{*}{ Severe } & $0.3 \pm 0.8$ & 0 & 0 & $1.1 \pm 1.2$ & $<0.001$ \\
\hline & $0.2-0.4$ & - & - & $0.8-1.5$ & \\
\hline
\end{tabular}

Abbreviation: COPD chronic obstructive pulmonary disease, NON-AE non-exacerbators, $A C O$ asthma-COPD overlap, $A E$ frequent exacerbators, $P B-F E V{ }_{1}$ post bronchodilator forced expiratory volume in $1 \mathrm{~s}$, SD standard deviation; $95 \% \mathrm{Cl}, 95 \%$ confidence interval $p$-values with bold are significant

for $\mathrm{AE}$ versus $\mathrm{ACO}$, as well as cough and daily activity limitation for ACO versus NON-AE. This lack of significance could be due to the smaller sample size of ACO, or the diurnal variation in symptomatology of bronchial asthma which is commonly associated with cough and sputum production.

The distribution of COPD phenotypes in the present study was almost similar to that of western populations, [24-27] except that AE NON-CB is less commonly reported than ACO [28]. So far, only two other studies have reported $\mathrm{AE} \mathrm{CB}$ is the commonest $\mathrm{COPD}$ phenotypes followed by NON-AE, AE NON-CB and ACO. The first study was conducted in primary care centres of the Russia Federation, [29] while the second study involved selected COPD patients in the respiratory clinic of a tertiary hospital [30]. Our findings of patients with $\mathrm{AE}$ being older and smoked more cigarettes, [25, $27,28,31]$ as well as more female patients with the ACO phenotype are in agreement with other studies [24, 26-28]. The finding that the HRQoL of COPD patients was more impaired in the phenotype sequence of NON$\mathrm{AE}, \mathrm{ACO}$ and $\mathrm{AE}$ is consistent with the findings of 
Table 2 mMRC, CAT and SGRQ-c scores of COPD patients according to their COPD phenotypes

\begin{tabular}{|c|c|c|c|c|}
\hline \multirow{2}{*}{$\begin{array}{l}\text { Quality of Life } \\
\text { Measurement }\end{array}$} & \multicolumn{4}{|c|}{ Clinical Phenotype, n (\%) } \\
\hline & $\begin{array}{l}\text { NON-AE } \\
108(58.4)\end{array}$ & $\begin{array}{l}\text { ACO } \\
26(14.1)\end{array}$ & $\begin{array}{l}\mathrm{AE} \\
51(27.6)\end{array}$ & $p$-value \\
\hline \multicolumn{5}{|l|}{ mMRC, n, (\%) } \\
\hline $0-1$ & $90(83.3)$ & $16(61.5)$ & $16(31.4)$ & \multirow[t]{2}{*}{$<0.001$} \\
\hline $2-4$ & $18(16.7)$ & $10(38.5)$ & $35(68.6)$ & \\
\hline \multicolumn{5}{|c|}{ CAT, score (mean $\pm \mathrm{SD}, 95 \% \mathrm{Cl})$} \\
\hline \multirow[t]{2}{*}{ Total } & $5.5 \pm 4.7$ & $11.7 \pm 8.6$ & $17.3 \pm 9.5$ & \multirow[t]{2}{*}{$<0.001$} \\
\hline & $4.6-6.4$ & $8.2-15.2$ & $14.6-19.9$ & \\
\hline \multirow[t]{2}{*}{ Cough } & $1.9 \pm 1.3$ & $2.6 \pm 1.1$ & $3.2 \pm 1.5$ & \multirow[t]{2}{*}{$<0.001$} \\
\hline & $1.7-2.2$ & $2.2-3.1$ & $2.8-3.6$ & \\
\hline \multirow[t]{2}{*}{ Mucus } & $1.3 \pm 1.2$ & $1.9 \pm 1.5$ & $2.5 \pm 1.6$ & \multirow[t]{2}{*}{$<0.001$} \\
\hline & $1.0-1.5$ & $1.3-2.5$ & $2.1-3.0$ & \\
\hline \multirow[t]{2}{*}{ Chest tightness } & $0.4 \pm 0.7$ & $1.4 \pm 1.4$ & $2.2 \pm 1.4$ & \multirow[t]{2}{*}{$<0.001$} \\
\hline & $0.3-0.5$ & $0.9-2.0$ & $1.9-2.6$ & \\
\hline \multirow[t]{2}{*}{ Walk uphill } & $0.9 \pm 1.1$ & $1.8 \pm 1.3$ & $2.7 \pm 1.5$ & \multirow[t]{2}{*}{$<0.001$} \\
\hline & $0.7-1.1$ & $1.3-2.3$ & $2.3-3.1$ & \\
\hline \multirow[t]{2}{*}{ Home activity } & $0.3 \pm 0.7$ & $1.2 \pm 1.5$ & $2.0 \pm 1.6$ & \multirow[t]{2}{*}{$<0.001$} \\
\hline & $0.2-0.5$ & $0.6-1.8$ & $1.5-2.4$ & \\
\hline \multirow[t]{2}{*}{ Leaving home } & $0.2 \pm 0.6$ & $0.9 \pm 1.1$ & $1.7 \pm 1.5$ & \multirow[t]{2}{*}{$<0.001$} \\
\hline & $0.1-0.3$ & $0.4-1.3$ & $1.2-2.1$ & \\
\hline \multirow[t]{2}{*}{ Sleep } & $0.2 \pm 0.6$ & $0.9 \pm 1.2$ & $1.2 \pm 1.2$ & \multirow[t]{2}{*}{$<0.001$} \\
\hline & $0.1-0.3$ & $0.4-1.4$ & $0.9-1.6$ & \\
\hline \multirow[t]{2}{*}{ Energy } & $0.3 \pm 0.6$ & $1.0 \pm 1.4$ & $1.8 \pm 1.5$ & \multirow[t]{2}{*}{$<0.001$} \\
\hline & $0.2-0.4$ & $0.5-1.6$ & $1.3-2.2$ & \\
\hline \multicolumn{5}{|c|}{ SGRQ-C, \% (mean \pm SD, 95\% Cl) } \\
\hline \multirow[t]{2}{*}{ Total } & $16.4 \pm 14.8$ & $34.4 \pm 19.5$ & $53.5 \pm 22.7$ & \multirow[t]{2}{*}{$<0.001$} \\
\hline & $13.5-19.2$ & $26.5-42.2$ & $47.1-59.8$ & \\
\hline \multirow[t]{2}{*}{ Symptoms } & $18.3 \pm 14.3$ & $41.9 \pm 16.1$ & $64.6 \pm 20.2$ & \multirow[t]{2}{*}{$<0.001$} \\
\hline & $15.5-21.0$ & $35.4-48.4$ & $58.9-70.3$ & \\
\hline \multirow[t]{2}{*}{ Activities } & $27.1 \pm 23.2$ & $36.3 \pm 19.4$ & $57.8 \pm 20.9$ & \multirow[t]{2}{*}{$<0.001$} \\
\hline & $22.6-31.5$ & $28.4-44.1$ & $52.0-63.7$ & \\
\hline Impact & $9.3 \pm 14.3$ & $30.6 \pm 26.1$ & $47.1 \pm 29.9$ & $<0.001$ \\
\hline & $6.6-12.1$ & $20.0-41.2$ & $38.7-55.5$ & \\
\hline
\end{tabular}

Abbreviation: COPD chronic obstructive pulmonary disease, NON-AE nonexacerbators, $A C O$ asthma-COPD overlap, $A E$ frequent exacerbators, $m M R C$ modified Medical Research Council, CAT COPD Assessment Test, SGRQ-c St George's Respiratory Questionnaire for COPD, SD standard deviation; $95 \% \mathrm{Cl}$, $95 \%$ confidence interval

$p$-values with bold are significant

previous studies $[24,26-28,32]$. Patients with $\mathrm{AE}$ are consistently highlighted as having the worst HRQoL, $[24,26-28,31,32]$ while those with NON-AE have the best HRQoL $[25,29]$. Of patients with AE, Miravitlles et al., [28] Cosio et al., [31] Kania et al., [27] and Chai et al., [30] reported those with AE-CB have significantly worse HRQoL compared to other COPD phenotypes (all $p<0.001$ ); while Corlatenau et al. reported the worst HRQoL in patients with AE NON-CB [32]. The CAT was uniformly used to asses HRQoL in these studies, with the latter two studies also using the SGRQ-c questionnaire. Only this study and that by Miravitlles et al., [28] show patients with ACO have significantly worse HRQoL than those with NON-AE.

Exacerbation is the prognostic hallmark of COPD. Frequent exacerbation is associated with poor HRQoL, [33] decline in lung function, [34] recurrence of exacerbations, [33] recurrent hospitalisations, [35] and increased mortality [36]. Seemungal et al. and Mackay et al., respectively reported COPD patients with $\geq$ three exacerbations (SGRQ-c, $p<0.001$ ) and $\geq$ two exacerbations (CAT, $p=0.025$ ) per year have significantly worse HRQoL [33, 37]. Cheng et al. also reported COPD frequent exacerbators have significantly worse HRQoL (mMRC, $p<0.001$; CAT, $p<0.001$ ) compared to nonfrequent exacerbators [38]. Therefore, this explains the significantly worse HRQoL among our patients with AE. Despite similar exacerbation frequency, our patients with ACO had significantly worse HRQoL than those with NON-AE which highlights that COPD subtypes can also affect the patients' HRQoL. Miravitlles et al. and Hardin et al., respectively reported COPD patients with BA have significantly worse HRQoL than those without [(mMRC, $p=0.008$; SGRQ-c, $p<0.001$ ), and (SGRQ-c, $p=0.008$ ), respectively $[39,40]$. Such a finding is not surprising in view of the presence of two different inflammatory processes in ACO.

The findings of our study support the recommendation of GesEPOC to phenotype every COPD patients based on their exacerbation frequency and COPD subtypes [15]. Besides, this study also highlights that exacerbation frequency supersedes COPD subtypes in determining the patients' HRQoL. Therefore, clinicians should manage COPD patients with frequent exacerbations more aggressively, and consider prescribing pharmacotherapies such as long-acting muscarinic antagonist (LAMA), LAMA and long-acting $\beta_{2}$-agonist in combination, inhaled corticosteroids (ICS), roflumilast, macrolide, or $\mathrm{N}$-acetylcysteine according to the COPD phenotype [1]. COPD treatment should also be personalised according to COPD subtypes, such as ICS for $\mathrm{ACO}$, roflumilast for $\mathrm{CB}$, and medical or surgical lung volume reduction for emphysema [1].

The present study is among the few in Asia that compares the HRQoL of COPD patients based on different clinical phenotypes. All the patients in this study were from the rural area. Their characteristics are very different from previous studies, such as having a high incidence of significant exposure to biomass fuel, required good physical fitness for agriculture activities, and had limited access to more expensive or newer COPD 


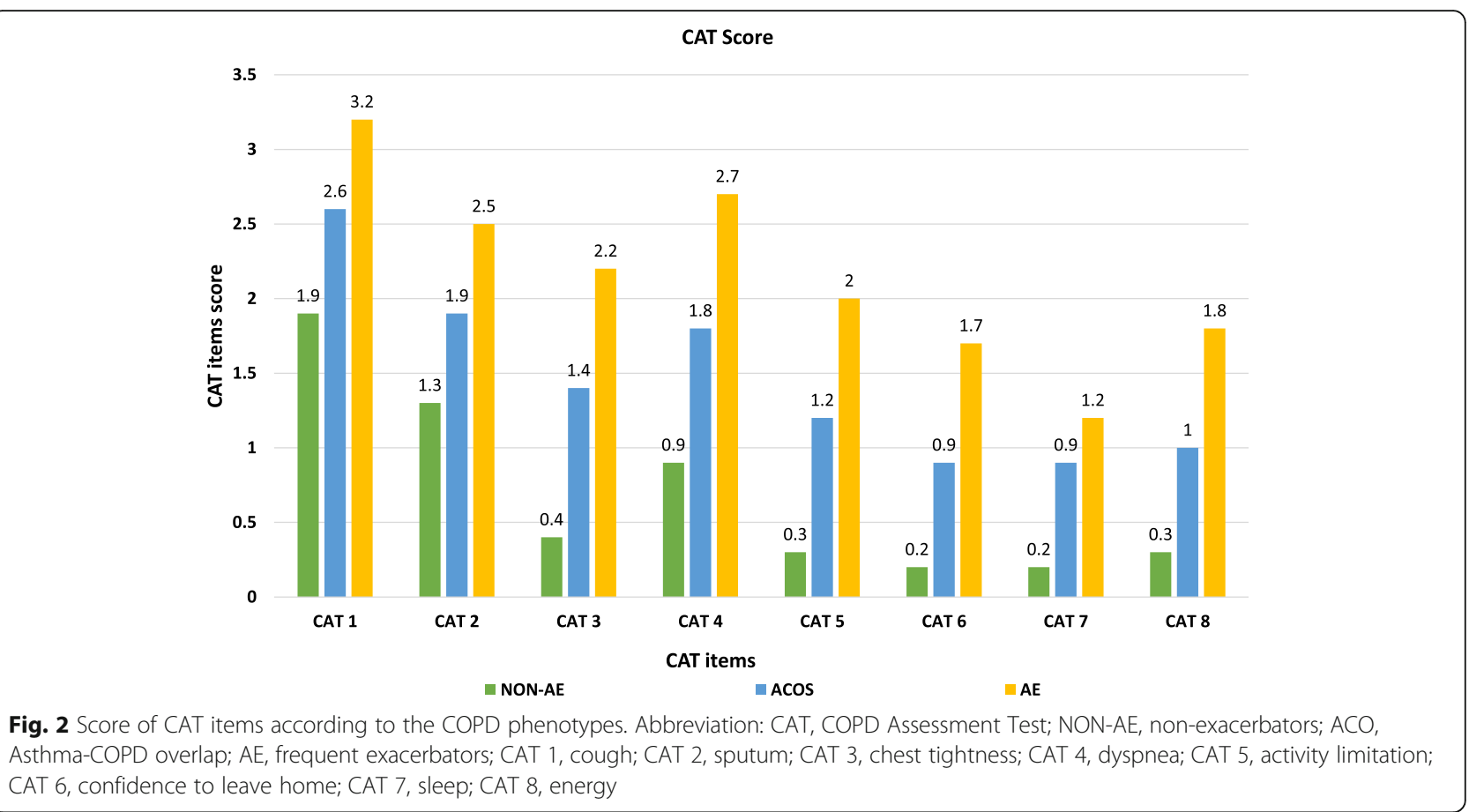

medications. Besides, we evaluated the HRQoL by using different HRQoL assessment tools and compared each of the subitem or component. By doing so we aimed to assess the patients' HRQoL in more dimensions and to minimise biases.

There were several limitations in this study. Firstly, the number of AE NON-CB patients was disproportionally small and therefore we were unable to analyse it independently. We added $\mathrm{AE}$ NON-CB to $\mathrm{AE}-\mathrm{CB}$, and analysed in the line of AE for HRQoL analysis. Secondly, the direct comparison of $\mathrm{CB}$ versus emphysema subtypes was not possible because of the first limitation. Thirdly, the AE NON-CB phenotype was based on the finding of air-trapping on physical examination and on chest Xray. Static lung volume measurement of functional residual capacity, residual volume and total lung capacity

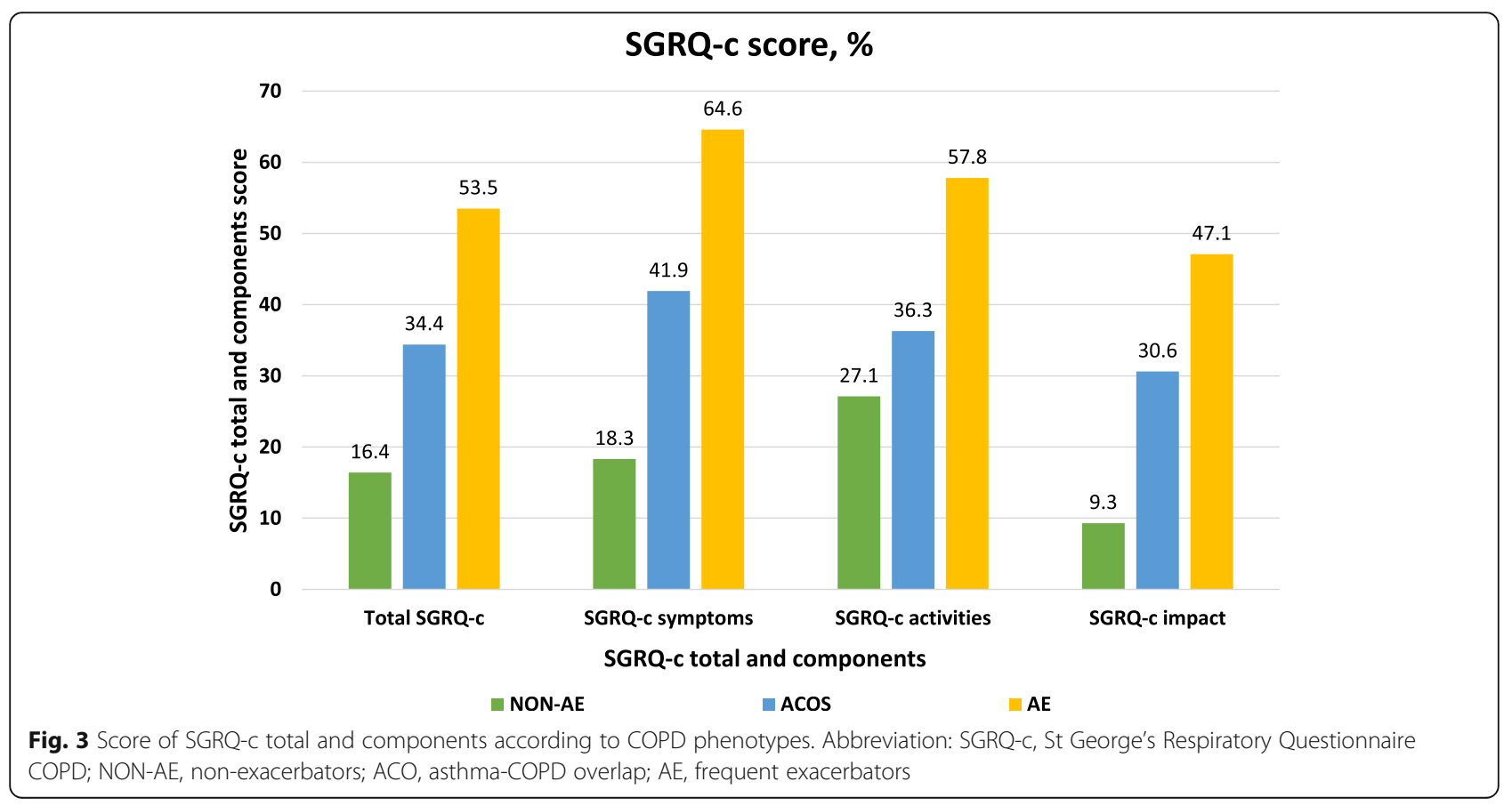


as well as non-contrast-enhanced thoracic computed tomography scan acquired at full inspiration and expiration that is able to differentiate emphysematous from non-emphysematous air-trapping were not performed [41]. Fourthly, spirometry used to identify COPD patients in this study utilised $\mathrm{FVC}_{6}$ instead of force vital capacity, potentially excluding a proportion of patients with mild COPD. Fifthly, body plethysmography and diffusion capacity for carbon monoxide (DLCO) were not performed. Studies have shown that body plethysmography and DLCO are more sensitive than spirometry in detecting early emphysema, evidenced by increase in residual volume and reduced DLCO [42]. Besides, COPD severity graded by using compression-free $\mathrm{FEV}_{1}$ measured by body plethysmograph is more accurate than $\mathrm{FEV}_{1}$ measured by spirometry [43]. Six, ACO in this study was defined based on a history of BA and very reversible airflow obstruction on spirometry testing. Blood eosinophil count was not routinely performed in the rural areas in Malaysia. The term ACO remains controversial without an agreed-upon definition [44]. Lastly, the exacerbation frequency was subjected to the recall error of the patients. We tried to minimize this error by confirmation from the patients' medical records and with the patients' family members.

\section{Conclusions}

The present study concludes that HRQoL of patients with different COPD phenotypes is not the same. Patients with $\mathrm{AE}$ had the worst HRQoL, followed by those with $\mathrm{ACO}$ and NON-CB, respectively. The findings of this study support the recommendation of GesEPOC to phenotype and manage COPD patients based on their exacerbation frequency and COPD subtypes. COPD management should be personalised and more aggressive in frequent exacerbators to improve their poor HRQoL.

\section{Abbreviations}

COPD: Chronic obstructive pulmonary disease; HRQoL: Health-related quality of life; PB-FEV1: Post-bronchodilator forced expiratory volume in $1 \mathrm{~s}$; PBFVC $_{6}$ : Post-bronchodilator forced vital capacity in $6 \mathrm{~s}$; mMRC: Modified Medical Research Council; CAT: COPD Assessment Test; SGRQ-c: St Georges Respiratory Questionnaire for COPD; PB-FEV $\%$ predicted: $\mathrm{PB}-\mathrm{FEV}_{1}$ in $\%$ of predicted; GesEPOC: Spanish COPD guideline; NON-AE: Non-exacerbator phenotype; AE: Exacerbator phenotype; $A E$ CB: Exacerbator phenotype with chronic bronchitis; AE NON-CB: Exacerbator phenotype with emphysema; BA: Bronchial asthma; ACO: Asthma-COPD overlap phenotype; SD: Standard deviation; 95\% Cl: 95\% confidence interval; LAMA: Long-acting muscarinic antagonist; ICS: Inhaled corticosteroids; DLCO: Diffusion capacity for carbon monoxide
\end{abstract}

\section{Acknowledgements}

We would like to thank the Director General of Health Malaysia for his permission to publish this article. We want to express our gratitude to all the patients who had participated in the study.

\section{Authors' contributions}

CSC, DLCN, ATS, MABI, ANBM, SBT, YKP and CKL contributed to the conception and design of the study; CSC, SBM, and DLCN contributed to the data acquisition; CSC, SBM, DLCN, GMKCG, ATS and SBT contributed to the data analysis and interpretation; CSC, DLCN, GMKCG, ATS, MABI, ANBM, SBT, YKP and CKL contributed to the drafting of the article and critically revising it. All authors made final approval of the version to be published. All authors agreed to be accountable for all aspects of the work in ensuring that questions related to the accuracy or integrity of the work are appropriately investigated and resolved.

\section{Funding}

This study was fully supported by the Research Acculturation Grant Scheme of the Ministry of Higher Education, Malaysia (RAGS/1/2015/SKKO2/UNIMAS/ 03/2 or FA052000-0708-0029). The funding body only financially supported this study, and did not take part in the design of the study; or collection, analysis, and interpretation of the data; or writing of the manuscript.

\section{Availability of data and materials}

The datasets used and/or analysed during the current study are available from the corresponding author on reasonable request.

\section{Ethics approval and consent to participate}

The ethics approval for this study was obtained from the Medical Research and Ethic Committee of National Medical Research Registry Malaysia (NMRR17-2549-38621) and the respective hospitals. Written informed consent was obtained from every patient.

\section{Consent for publication}

Not applicable.

\section{Competing interests}

The authors declare no potential conflicts of interest in respect to the research, authorship, and publication of this article.

\section{Author details}

${ }^{1}$ Department of Medicine, Faculty of Medicine and Health Science, University Malaysia Sarawak, Kota Samarahan, Sarawak, Malaysia. ${ }^{2}$ Department of Nursing, Faculty of Medicine and Health Science, University Malaysia Sarawak, Kota Samarahan, Sarawak, Malaysia. ${ }^{3}$ Department of Community Medicine and Public Health, Faculty of Medicine and Health Science, University Malaysia Sarawak, Kota Samarahan, Sarawak, Malaysia. ${ }^{4}$ Department of Medicine, Faculty of Medicine, University Technology MARA, Sungai Buloh, Selangor, Malaysia. ${ }^{5}$ Department of Medicine, Faculty of Medicine, University of Malaya, Kuala Lumpur, Malaysia.

Received: 10 June 2020 Accepted: 16 September 2020

Published online: 29 September 2020

\section{References}

1. GOLD. Global Strategy for the Diagnosis, Management and Prevention of COPD, Global Initiative for Chronic Obstructive Lung Disease (GOLD) 2020 [Available from: https://goldcopd.org/.].

2. Lozano R, Naghavi M, Foreman K, Lim S, Shibuya K, Aboyans V, et al. Global and regional mortality from 235 causes of death for 20 age groups in 1990 and 2010: a systematic analysis for the global burden of disease study 2010. Lancet. 2012;380(9859):2095-128.

3. Murray CJ, Lopez AD. Measuring the global burden of disease. N Engl J Med. 2013;369(5):448-57.

4. Han MK, Agusti A, Calverley PM, Celli BR, Criner G, Curtis JL, et al. Chronic obstructive pulmonary disease phenotypes: the future of COPD. Am J Respir Crit Care Med. 2010;182(5):598-604.

5. Snider GL. Chronic Obstructive Pulmonary Disease: A Definition and Implications of Structural Determinants of Airflow Obstruction for Epidemiology. Am Rev Respir Dis. 1989;140(3_pt_2):S3-8.

6. Miravitlles M, Soler-Cataluna JJ, Calle M, Molina J, Almagro P, Quintano JA et al. Spanish COPD guidelines (GesEPOC): pharmacological treatment of stable COPD. Spanish society of pulmonology and thoracic surgery. Archivos de bronconeumologia. 2012;48(7):247-57. 
7. Fayers PM, M D. Quality of life the assessment, analysis and interpretation of patient-reported outcomes. 2nd ed. West Sussex: John Wiley \& Sons Ltda: 2007.

8. Miravitlles M, Ribera A. Understanding the impact of symptoms on the burden of COPD. Respir Res. 2017;18(1):67.

9. Buist AS, McBurnie MA, Vollmer WM, Gillespie S, Burney P, Mannino DM, et al. International variation in the prevalence of COPD (the BOLD study): a population-based prevalence study. Lancet. 2007;370(9589):741-50.

10. Charan J, Biswas T. How to calculate sample size for different study designs in medical research? Indian J Psychol Med. 2013;35(2):121-6.

11. Cigarette smoking among adults and trends in smoking cessation - United States, 2008. MMWR Morbidity and mortality weekly report. 2009;58(44): 1227-32. https://pubmed.ncbi.nlm.nih.gov/19910909/\#: :text=This\%2 Oreport\%20summarizes\%20the\%20results,\%25)\%20to\%202008\%20(20.6\%25).

12. Montes de Oca M, Zabert G, Moreno D, Laucho-Contreras ME, Lopez Varela MV, Surmont F. Smoke, biomass exposure, and COPD risk in the primary care setting: the PUMA study. Respir Care. 2017:62(8):1058-66.

13. Ostrowski S, Barud W. Factors influencing lung function: are the predicted values for spirometry reliable enough? J Physiol Pharmacol. 2006;57(Suppl 4):263-71

14. Hurst JR, Vestbo J, Anzueto A, Locantore N, Mullerova $\mathrm{H}$, Tal-Singer $\mathrm{R}$, et al. Susceptibility to exacerbation in chronic obstructive pulmonary disease. N Engl J Med. 2010;363(12):1128-38.

15. Miravitlles M, Soler-Cataluna JJ, Calle M, Molina J, Almagro P, Quintano JA, et al. Spanish guidelines for Management of Chronic Obstructive Pulmonary Disease (GesEPOC) 2017. Pharmacological treatment of stable phase. Archivos de bronconeumologia. 2017;53(6):324-35.

16. Burgel P-R. Chronic cough and sputum production: a clinical COPD phenotype? Eur Respir J. 2012;40(1):4.

17. Sarkar M, Bhardwaz R, Madabhavi I, Modi M. Physical signs in patients with chronic obstructive pulmonary disease. Lung India. 2019;36(1):38-47.

18. Miravitlles M, Alvarez-Gutierrez FJ, Calle M, Casanova C, Cosio BG, LópezViña A, Pérez de Llano L, Quirce S, Roman-Rodríguez M, Soler-Cataluña Juan J et al. Algorithm for identification of asthma-COPD overlap: consensus between the Spanish COPD and asthma guidelines. Eur Respir J. 2017;49(5): 1700068.

19. Hajiro T, Nishimura K, Tsukino M, Ikeda A, Koyama H, Izumi T. Analysis of clinical methods used to evaluate dyspnea in patients with chronic obstructive pulmonary disease. Am J Respir Crit Care Med. 1998;158(4): 1185-9.

20. Jones PW, Harding G, Berry P, Wiklund I, Chen WH, Kline LN. Development and first validation of the COPD assessment test. Eur Respir J. 2009;34(3): 648-54.

21. Pinto LM, Gupta N, Tan W, Li PZ, Benedetti A, Jones PW, et al. Derivation of normative data for the COPD assessment test (CAT). Respir Res. 2014;15(1):68.

22. Meguro M, Barley EA, Spencer S, Jones PW. Development and validation of an improved, COPD-specific version of the St. George Respiratory Questionnaire. Chest. 2007;132(2):456-63.

23. Ferrer M, Villasante C, Alonso J, Sobradillo V, Gabriel R, Vilagut G, et al. Interpretation of quality of life scores from the St George's respiratory questionnaire. Eur Respir J. 2002;19(3):405-13.

24. Koblizek V, Milenkovic B, Barczyk A, Tkacova R, Somfay A, Zykov K, Tudoric N, Kostov K, Zbozinkova Z, Svancara J et al. Phenotypes of COPD patients with a smoking history in Central and Eastern Europe: the POPE Study. Eur Respir J. 2017:49(5):1601446.

25. Alcázar-Navarrete B, Trigueros JA, Riesco JA, Campuzano A, Pérez J. Geographic variations of the prevalence and distribution of COPD phenotypes in Spain: "the ESPIRAL-ES study". Int J Chron Obstruct Pulmon Dis. 2018;13:1115-24.

26. Calle Rubio M, Casamor R, Miravitlles M. Identification and distribution of COPD phenotypes in clinical practice according to Spanish COPD guidelines: the FENEPOC study. Int J Chron Obstruct Pulmon Dis. 2017;12: 2373-83.

27. Kania A, Krenke R, Kuziemski K, Czajkowska-Malinowska M, CelejewskaWójcik N, Kuźnar-Kamińska B, et al. Distribution and characteristics of COPD phenotypes - results from the polish sub-cohort of the POPE study. Int J Chron Obstruct Pulmon Dis. 2018;13:1613-21.

28. Miravitlles M, Barrecheguren M, Roman-Rodriguez M. Frequency and characteristics of different clinical phenotypes of chronic obstructive pulmonary disease. Int J Tuberc Lung Dis. 2015;19(8):992-8.
29. Arkhipov V, Arkhipova D, Miravitlles M, Lazarev A, Stukalina E. Characteristics of COPD patients according to GOLD classification and clinical phenotypes in the Russian Federation: the SUPPORT trial. Int J Chron Obstruct Pulmon Dis. 2017;12:3255-62.

30. Chai C-S, Liam C-K, Pang Y-K, Ng DL-C, Tan S-B, Wong T-S, et al. Clinical phenotypes of COPD and health-related quality of life: a cross-sectional study. Int J Chron Obstruct Pulmon Dis. 2019;14:565-73.

31. Cosio BG, Soriano JB, López-Campos JL, Calle M, Soler JJ, De-Torres JP, et al. Distribution and Outcomes of a Phenotype-Based Approach to Guide COPD Management: Results from the CHAIN Cohort. Plos One. 2016;11(9): e0160770.

32. Corlateanu A, Botnaru V, Rusu D, Scutaru E, Covantev S. Assessment of health-related quality of life in different phenotypes of COPD. Eur Respir J. 2017;50(suppl 61):PA3581.

33. Seemungal TA, Donaldson GC, Paul EA, Bestall JC, Jeffries DJ, Wedzicha JA. Effect of exacerbation on quality of life in patients with chronic obstructive pulmonary disease. Am J Respir Crit Care Med. 1998;157(5 Pt 1):1418-22.

34. Donaldson GC, Seemungal TAR, Bhowmik A, Wedzicha JA. Relationship between exacerbation frequency and lung function decline in chronic obstructive pulmonary disease. Thorax. 2002;57(10):847-52.

35. Garcia-Aymerich J, Farrero E, Felez MA, Izquierdo J, Marrades RM, Anto JM. Risk factors of readmission to hospital for a COPD exacerbation: a prospective study. Thorax. 2003;58(2):100-5.

36. Soler-Cataluna JJ, Martinez-Garcia MA, Roman Sanchez P, Salcedo E, Navarro M, Ochando R. Severe acute exacerbations and mortality in patients with chronic obstructive pulmonary disease. Thorax. 2005;60(11):925-31.

37. Mackay AJ, Donaldson GC, Patel AR, Jones PW, Hurst JR, Wedzicha JA. Usefulness of the chronic obstructive pulmonary disease assessment test to evaluate severity of COPD exacerbations. Am J Respir Crit Care Med. 2012; 185(11):1218-24.

38. Cheng Y, Tu X, Pan L, Lu S, Xing M, Li L, et al. Clinical characteristics of chronic bronchitic, emphysematous and ACOS phenotypes in COPD patients with frequent exacerbations. Int J Chron Obstruct Pulmon Dis. 2017;12:2069-74.

39. Miravitlles M, Soriano JB, Ancochea J, Munoz L, Duran-Tauleria E, Sanchez G, et al. Characterisation of the overlap COPD-asthma phenotype. Focus on physical activity and health status. Respir Med. 2013;107(7):1053-60.

40. Hardin M, Silverman EK, Barr RG, Hansel NN, Schroeder JD, Make BJ, et al. The clinical features of the overlap between COPD and asthma. Respir Res. 2011;12(1):127.

41. Occhipinti M, Paoletti M, Bigazzi F, Camiciottoli G, Inchingolo R, Larici AR, et al. Emphysematous and nonemphysematous gas trapping in chronic obstructive pulmonary disease: quantitative $C T$ findings and pulmonary function. Radiology. 2018;287(2):683-92.

42. Zanforlin A, Sorino C, Sferrazza Papa GF. Towards a multi-dimensional approach to COPD. Minerva Med. 2016;107(3 Suppl 1):1-6.

43. Pellegrino R, Crimi E, Gobbi A, Torchio R, Antonelli A, Gulotta C, et al. Severity grading of chronic obstructive pulmonary disease: the confounding effect of phenotype and thoracic gas compression. J Applied Physiol (Bethesda, Md : 1985). 2015;118(7):796-802.

44. Zeki AA, Jarjour NN. The asthma-chronic obstructive pulmonary disease overlap syndrome: a new take on an old concept. Ann Am Thorac Soc. 2016;13(9):1440-2.

\section{Publisher's Note}

Springer Nature remains neutral with regard to jurisdictional claims in published maps and institutional affiliations.

\section{Ready to submit your research? Choose BMC and benefit from}

- fast, convenient online submission

- thorough peer review by experienced researchers in your field

- rapid publication on acceptance

- support for research data, including large and complex data types

- gold Open Access which fosters wider collaboration and increased citations

- maximum visibility for your research: over $100 \mathrm{M}$ website views per year

At $\mathrm{BMC}$, research is always in progress.

Learn more biomedcentral.com/submission 